\title{
Gastrointestinal aspects of autonomic neuropathy: hidden dangers
}

\author{
Tamás Várkonyi ${ }^{1 *}$, Szabolcs Nyiraty ${ }^{1}$, Anna Körei ${ }^{2}, Z_{\text {suzsanna Putz }}{ }^{2}$, Csaba Lengyel ${ }^{1}$ and Péter Kempler ${ }^{2}$ \\ ${ }^{1}$ First Department of Internal Medicine, University of Szeged, Szeged, Hungary \\ ${ }^{2}$ First Department of Internal Medicine, Semmelweis University, Budapest, Hungary
}

Cardiovascular autonomic neuropathy (CAN) is usually considered as the most important manifestation of autonomic neuropathy. However, gastrointestinal autonomic disturbances are also very frequent and mostly underdiagnosed. There is an important difference between cardiovascular and gastrointestinal manifestations. In the case of CAN, we observe usually a sequelae of alterations: parasympathetic autonomic neuropathy with sympathetic overactivity are dominating for quite a long period, followed by parasympathetic and sympathetic denervation. In paralell with this, in most cases CAN is subclinical, while clinical symptoms occur only later $[1,2]$.

This hierarchy of sequelae usually cannot be observed among patients with gastrointestinal autonomic involvement. The explanation is that neural regulation of gastrointestinal motility is more complex, beside the central autonomic and enteric denervation. It involves interstitial cells of Cajal as well. Moreover, metabolic and electrolyte disturbances and effects of some antidiabetic drugs also influence gastrointestinal motility $[3,4]$. In the present editorial, a few aspects important for general practicioners and internist will be outlined.

Diabetic gastroparesis is considered as the most relevant clinical consequence of gastrointestinal autonomic neuropathy. The characteristic clinical symptoms include early satiety, abdominal fullness, nausea and vomiting [4,5]. The diagnosis of gastroparesis is more easy among patients referred with these symptoms, in many cases the patients are seen by gastroenterologists. However, in about half of the patients with gastroparesis, these typical symptoms are not present. How can this complication be diagnosed in these cases? Gastroparesis is a late diabetic complication and patients are treated in almost all cases with insulin. Due to severely impaired motility, food absorption is delayed with a consequence of gastric hypoglycaemia usually observed in the form of postprandial hypoglycaemia [6]. Following the hypoglycaemic episodes quite often prolonged hyperglycaemia can be observed due to prolonged food absorption and increased activity of contrainsulinotropic hormones.

Gastroparesis should always be taken into consideration if episodes of unexplained hypo- and hyperglycaemia are present in an insulin treated diabetic patient with long diabetes duration, especially before establishing the diagnosis of the so-called brittle diabetes. Recently, we have reported on a case of a patient with pancreatogenic diabetes: the patient has been referred due to recurrent episodes of unconsciousness caused by postprandial hypoglycaemia to the Department of Neurology
[7]. Application of continuous glucose monitoring (CGM) revealed the serious repetitive hypoglycemias after breakfast and dinner (Figure 1). In the management of patients with gastroparesis, short acting insulins should be avoided and long acting insulins, preferably analogues should be preferred, while the patient should be encouraged to eat even before the administration of insulin.

Painless or silent myocardial infarction is one of the most severe complications of CAN. Importantly, some symptoms suggesting an infarction may occur in diabetic patients with painless but not silent myocardial infarction. Heart failure and collapse are the most well-known among them, but nausea and even vomiting should be taken into consideration as well, especially among patients with gastrointestinal autonomic dysfunction. Acute myocardial infarction is always associated with hyperglycemia, while hyperglycemia is accompanied by acute impairment of gastrointestinal motility. If subclinical gastrointestinal autonomic neuropathy is already present, the consequence is often nausea and vomiting.

Interestingly, diarrhea, incontinence and constipation might all be the consequence of the development of autonomic neuropathy in the small and large bowels [8]. The explanation of the symptom diversity is that a high number of regulating neuronal networks and factors are impaired in the intestinal manifestation of neuropathy (parasympathetic and sympathetic nervous systems, enteric nerves, interstitial cells of Cajal, gastrointestinal peptides, microbiota etc).

The lazy, large gallbladder was considered as a typical autonomic manifestation for many decades. Since the time we stopped using intravenous cholangiography, this diagnosis is no longer in use. However, the clinical findings are still the same: the large neuropathic gallbladder typically full with gallstones seen at the ultrasound scan can easily be misinterpreted as acute inflammatory gallstone disease. In a biliary scintigraphy trial we have proven a strict correlation between the severity of autonomic neuropathy and the hypomotility of the gallbladder in diabetic patients [9]. Nonetheless, similarly to painless myocardial infarction, even silent or painless acute abdomen might occur among diabetic patients with severe autonomic dysfunction.

Correspondence to: Tamás Várkonyi, First Department of Internal Medicine, University of Szeged, Szeged, Hungary, E-mail: varkonyitamas@gmail.com

Received: July 14, 2017; Accepted: July 25, 2017; Published: July 27, 2017 


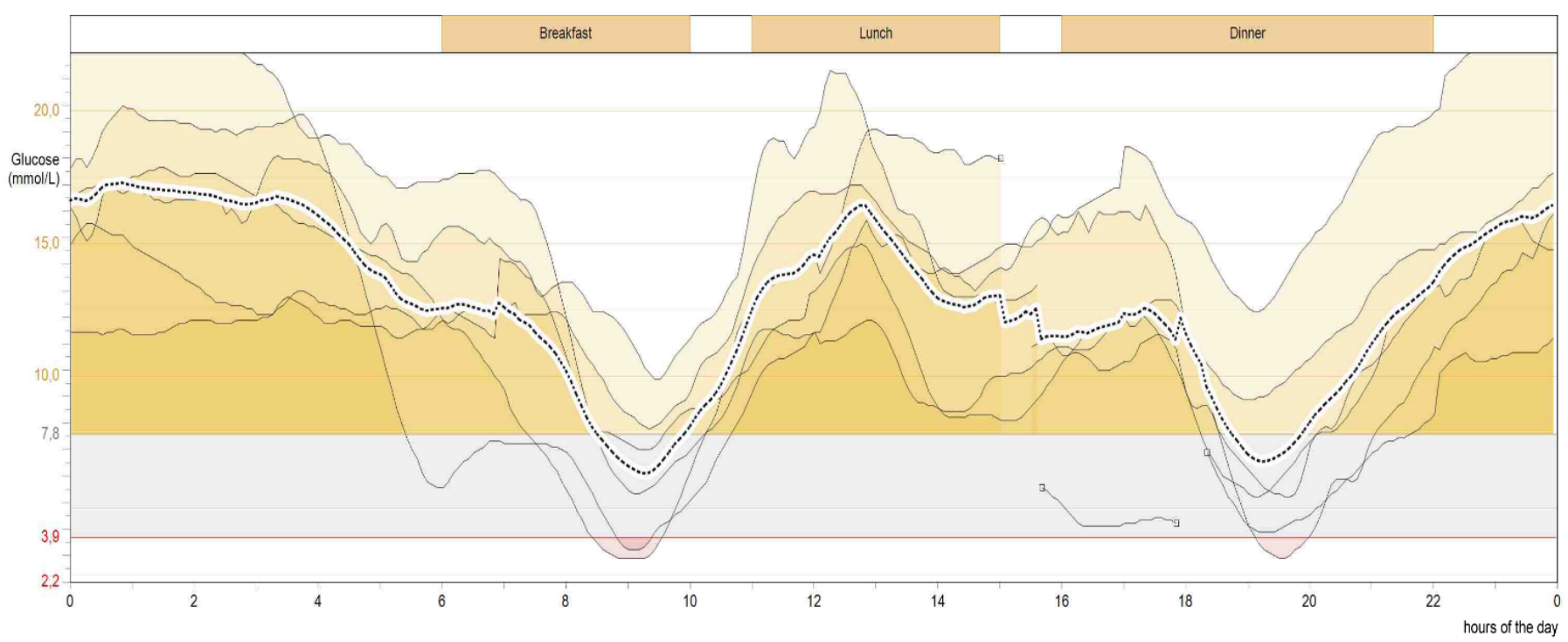

Figure 1. Interstitial glucose levels measured by CGM method of a patient on 6 consecutive days with severe gastroparesis [7].

\section{References}

1. Tesfaye S, Boulton AJM, Dyck PJ, Freeman R, Horowitz M, et al. (2010) Diabetic neuropathies: update on definitions, diagnostic criteria, estimation of severity, and treatments. Diabetes Care 33: 2285-2293. [Crossref]

2. Spallone V, Ziegler D, Freeman R, Bernardi L, Frontoni S, et al. (2011) Cardiovascular autonomic neuropathy in diabetes: Clinical impact, assessment, diagnosis, and management. Diabetes Metab Res Rev 27: 639-653. [Crossref]

3. Kempler P, Ameranco G, Freeman R, Frontoni S, Horowitz M, et al. (2011) Gastrointestinal autonomic neuropathy, erectile-, bladder-and sudomotor dysfunction in patients with diabetes mellitus: clinical impact, assessment, diagnosis and management. Diabetes Metab Res Rev 27: 665-677.

4. Kempler P, Várkonyi T, Körei AE, Horváth VJ (2016) Gastrointestinal autonomic neuropathy in diabetes: the unattended borderline between diabetology and gastroenterology. Diabetologia 59: 401-403. [Crossref]
5. Horváth V, Izbéki F, Lengyel Cs, Kempler P, Várkonyi T (2014) Diabetic gastroparesis: functional/morphologic background, diagnosis and treatment options. Curr Diab Rep 14: 527. [Crossref]

6. Horowitz M, Jones KL, Rayner CK, Read NW (2006) 'Gastric' hypoglycaemia: an important concept in diabetes management. Neurogastroenterol Motil 18: 405-407. [Crossref]

7. Nyiraty Sz, Fehértemplomi K, Orosz A, Lengyel Cs, Ábrahám Gy, et al. (2017) Recurrent hypoglycemias caused by neuropathy in a patient with pancreatogenic diabetes. A case report. Diab Hung 25: 117-124.

8. Horváth VJ, Putz Z, Izbéki F, Körei AE, Gerő L, et al. (2015) Diabetes-related dysfunction of the small intestine and the colon: focus on motility. Curr Diab Rep 15: 94. [Crossref]

9. Várkonyi TT1, Lengyel C, Madácsy L, Velösy B, Kempler P, et al. (2001) Gallbladder hypomotility in diabetic polyneuropathy. Clin Auton Res 11:377-381. [Crossref]

Copyright: $@ 2017$ Várkonyi T. This is an open-access article distributed under the terms of the Creative Commons Attribution License, which permits unrestricted use, distribution, and reproduction in any medium, provided the original author and source are credited. 